\title{
Preliminary Study for Development of Auditory Training Tool Using Story and Question
}

\author{
Eun Hee Lim, Junghwa Bahng \\ Department of Audiology, Hallym University of Graduate Studies, Seoul, Korea \\ 이야기와 질문을 이용한 청능훈련 도구개발에 관한 연구 \\ 임 은 희·방 정 화 \\ 한림국제대학원대학교 청각학과
}

\begin{abstract}
Purpose: This study aims to develop auditory training materials using stories for adults and the elderly hearing-impaired listeners. Each story was composed of two sentences and one questionnaire. The new 200 stories are developed which are categorized into four main topics, Korean culture, cuisine, traditional game, and tourist attraction. Twelve normal hearing adults were administrated to verify difficulty of the stories, and 175 out of 200 stories were selected. Methods: To test validity and difficulty of each story and question, a total of 36 subjects with normal hearing listeners participated. Among 175 stories, 79 stories had type I questions, and the 96 stories had type II questions. Each story and the related question were presented at an individual most comfortable level at $6 \mathrm{~dB}$ signal-to-noise ratio condition through a loud speaker. Results: The results showed that 160 stories scored $100 \%$ of correct response rate, ten stories scored 90-99\%, three stories scored 80-89\%, and two stories scored 0\%. Also, there were no differences between stories with the different type of questions. Conclusion: These results showed that a total of 170 stories are appropriate for the auditory training tool. Future research is needed to demonstrate whether developed training tool is useful to improve communication skills for hearing-impaired listeners.
\end{abstract}

Key Words: Auditory training, Aural rehabilitation, Hearing-impaired.

Received: March 15, 2016 / Revised: April 4, 2016 / Accepted: April 11, 2016

Correspondence: Junghwa Bahng, Department of Audiology, Hallym University of Graduate Studies, 405 Yeoksam-ro, Gangnam-gu, Seoul 06198, Korea Tel: +82-70-8680-6933 / Fax: +82-2-3453-6618 / E-mail: bahng.jh@gmail.com

\section{INTRODUCTION}

우리나라는 평균수명이 늘어남과 동시에 출산율이 점점 감 소하여 노인인구의 비율이 증가하고 있다. 국민건강보험공단은 2014년 자료에서 2000년부터는 노인인구가 총 인구의 7\% 이상 으로 고령화 사회로 진입하였고 노인인구 비율이 2000년에는 $7.3 \%, 2006$ 년에는 $8.6 \%, 2010$ 년에는 $10.2 \%, 2013$ 년에는 $11.5 \%$ 로 노인인구 증가의 속도가 매우 빠르다고 보고하였다(Korean Institute for Health and Social Affaire, 2016). 노인인구의 증 가로 인하여 노인성 질환의 발병률도 증가하여 노화로 인한 노 인성 난청의 인구도 증가하는 추세이다(American SpeechLanguage-Hearing Association, 2016).

노인성 난청의 대표적인 중재방법은 인공와우 혹은 보청기
등의 보장구를 사용하여 가청력(audibility)을 개선하는 것이다. 인공와우의 경우 수술적인 부담이 있어 보청기를 착용하는 인 구가 증가하고 있으나 보청기에 대한 적응 실패로 착용을 거부 하는 비율 또한 높게 나타난다(Ku et al., 2006). 보청기 착용을 거부하는 가장 큰 이유는 보청기를 착용해도 소음상황에서 단 어인지도(word recognition score, WRS) 및 소리의 방향을 탐 지하는 데 어려움이 해결되지 않아 의사소통의 개선이 미비하 기 때문이다(Lee \& Lee, 2008). 생활환경에서 의사소통의 어 려움이 가중되면 학업, 직업의 문제는 물론 대인관계 위축 등 으로 이어져 심리적인 불안함과 소외감이 발생하고 이로 인해 우울증을 겪을 수도 있다(Park, 2009).

보청기 착용 후 의사소통 개선을 위한 방법으로 Burk \& Humes(2008)는 음향학적 소음 대 잡음 비(signal-to-noise ra- 
tio, SNR) 향상을 위한 방향성 마이크, 소음 감소 알고리즘 등 의 기술적인 방법 이외에 난청인이 소음 속 상황에서 인지능력 향상을 위한 청능훈련(auditory training)을 강조하고 있다. 신 경가소성(neuroplasticity)에 의해 우리의 뇌가 새로운 소리에 대해 순응하기 위해서는 일정 시간이 필요하며(Stacey et al., 2010; Sweetow \& Palmer, 2005), 청능훈련은 새로운 소리에 대 한 뇌의 적응을 가속화할 수 있고 소리에 대한 집중력의 증가로 인하여 의사소통의 개선의 효과를 볼 수 있다(Yeo et al., 2014). Lee \& Lee(2008)도 보청기 착용에 대한 만족도를 높이기 위해 서는 청각전문가가 개별화 계획에 근거하여 청능훈련을 실시하 는 것이 중요하다고 강조하였다.

국외의 경우는 여러 청능훈련 도구들이 개발되었는데 대표 적으로 Listening and Communication Enhancement (LACE; Sweetow \& Sabes, 2006)는 빠른 말소리 인지, 소음 하 상황에 서 문장 인지, 단어 기억하기 등이 포함되어 있으며, eARena (Siemens, 2007)는 흥미를 유발하여 자발적으로 참여하도록 하고 유사한 단어, 소음 하 상황에서 문장 인지, 환경음 찾기 등이 포함되어 있다. 이러한 해외의 도구들은 영어를 근간으로 하기 때문에 우리나라에 도입해서 훈련에 이용은 불가능하다. 국내에서도 난청인의 보장구에 대한 만족도의 향상과 함께 의 사소통 능력의 증진을 위한 청능훈련 프로그램의 중요성을 인 식하고 한국 노인 및 성인 난청인을 위하여 청능훈련 프로그램 개발을 위하여 훈련 시 사용할 컨텐츠가 여럿 개발되었다. 환 경음(Ahn, 2016), 가로세로 단어판을 이용한 단어 듣기(Baek, 2016), 문장(Jang, 2016) 등이 현재 개발되었다. 국내에서 최근 발표된 청능훈련에 관한 연구에서는 소음 속 상황에서 어려워 하는 무의미단음절을 이용하여 난청노인에게 12 주간 청능훈련 을 실시한 결과 무의미단음절에 대한 어음인지도가 $41 \%$ 향상 되었다고 보고하였고(Lee, 2011), 6주 동안 소음 하 문장을 사 용해 청능훈련을 실시한 결과 소음 하 문장인지도가 유의하게 향상되었고 보청기 사용에 대한 만족도 또한 증가하였다고 밝 혔다(Yeo et al., 2014). 또한 8주간의 청능훈련을 통해 소음 하 어음 인지도의 향상과 보청기 착용의 만족도가 증가한다고 보 고하였다(Cho et al., 2013; Kwon, 2014). 현재까지 국내 발표한 논문들을 살펴보면 3 7개의 어절로 이루어진 문장수준에서의 훈련이 가장 상위단계의 자극이다. 그러나 난청인들의 의사소 통의 증진을 위해서는 한 문장씩 듣고 이해하는 것도 중요하지 만 여러 문장으로 이루어진 이야기를 듣고 기억하여 요지를 파 악하는 능력 또한 필요하다. 한 예로, Park et al.(2009)은 이야 기를 듣고 관련 질문에 답하는 훈련을 통하여 이야기의 중심 줄거리를 파악하고 질문의 답을 추론하는 능력을 향상시킬 수 있음을 보고하였다.

본 연구의 목적은 청능재활의 가장 상위 인지 단계인 이해능
력 향상에 활용 가능한 이야기 훈련 도구를 개발하는 것이다. 이야기 도구를 사용한 청능훈련은 보청기나 인공와우 착용자 가 이야기의 핵심 내용을 파악하고 답변을 추론하는 상위 이해 능력을 향상 시키는 데 도움을 줄 수 있을 것으로 생각한다. 훈 련 시 이야기를 잘 듣고 이해하였는지 확인하기 위하여 질문을 포함시켰으며, 두 가지 유형으로 개발하였다. 이야기 청능훈련 도구의 개발은 다음 두 가지 목적을 가지고 이야기를 개발하였 다. 첫째, 이야기의 내용은 한국의 실정에 맞아야 한다. 둘째, 정상청력을 가진 성인이 들었을 때 이야기를 쉽게 이해할 수 있 어야 한다.

\section{MATERIALS AND METHODS}

\section{이야기목록 개발}

난청인의 보청기를 착용 후 의사소통 능력 향상을 위한 청능 훈련용 이야기의 선정 과정은 다음과 같다.

\section{이야기목록 수집}

청능훈련으로 사용할 수 있도록 친숙한 단어들로 이루어진 문장들을 얻기 위하여 우리나라의 문화, 음식, 전통놀이, 여행 지 등을 중심으로 이야기를 선정하되 전문적인 용어가 포함되 지 않도록 하였다. 각 이야기는 2 개의 문장으로 구성하며 답안 이 되는 단어는 두 번 이상 포함되도록 하였다. 총 400 문항의 문장을 만들어 200 문항의 이야기를 완성하였고, 이야기 뒤에 제시되는 질문의 유형을 두 가지로 하였다. 질문을 통해 집중 듣기를 한 번 더 할 수 있는 방법과 전체적인 내용을 이해하는 가를 묻는 방법이다. 첫 번째 유형(type I)은 이야기 속에 포함 되어 있는 내용을 질문을 통해 다시 듣게 하는 방법이다. 65 번 문항을 예로 들자면 “수라상은 궁중에서 평상시에 임금에게 올 리는 아침과 저녁상입니다. 수라상은 기본 찬 이외에 열두 가지 를 놓은 십이 첩 반상입니다.”라는 이야기를 들려준 후 “궁중에 서 임금에게 올리는 아침과 저녁상으로 올리는 십이 첩 반상인 이것의 이름은 무엇인가요?"라는 방식으로 질문을 통해 이야기 의 주요단어를 한 번 더 듣기를 할 수 있다. 두 번째 유형(type II)은 불특정하게 질문하는 방법으로 163 번 문항을 예로 들면 "한지는 닥나무 껍질을 삶고 으깨어 만든 종이입니다. 한지는 습기에 강하고 보존성이 좋아 천년을 가는 우리나라 전통 종이 입니다.”라는 이야기를 들려준 후 “무엇에 대하여 이야기 하고 있나요?"라는 방식으로 불특정하게 질문을 하였다. 이야기의 다른 예시는 Appendix에 제시하였다.

\section{1차 이야기목록 타당성 검증}

수집한 200문항의 이야기목록들에 대한 타당성 검증을 위 
해서 건청 성인 20대 6명(남 3명, 여 3명), 40 50대 6명(여 2명, 남 4명)으로 총 12명(평균 35.9세, 표준편차 13.5)이 참가하였다. 이때에는 검사자가 육성으로 조용한 방에서 이야기를 읽어 주 고 피검자는 해당하는 답을 적으며 그와 동시에 문장이 이해 가능한지, 친숙하지 않은 단어가 사용되었는지를 피검자의 주 관적 생각을 바탕으로 쉬움 100점, 보통 50점, 어려움 0점으로 점수화하도록 하였다. 200 문항 중 평균적으로 50점 이하로 판 단한 25 문항을 제외하고 총 175 문항을 선정하였다.

\section{2차 검증을 위한 이야기목록 음원 제작}

선정된 175 문항의 이야기들을 음원 녹음을 위해 표준말을 사용하는 20 대 성인의 여성 1 명이 발화하여 녹음하였다. 녹음 을 위해 방음부스에서 오디오 인터페이스(M-AUDIO fast Track Pro, Sound ocean, Taipei, Taiwan)와 SM300(Relacart Electronics Co. Ltd., San Francisco, CA, USA) 마이크를 이용하 여 녹음하였고 마이크와 화자의 입 사이의 거리는 $15 \mathrm{~cm}$ 가 되 도록 유지하였다. 녹음 시 표본화 주파수와 비트는 $44,100 \mathrm{~Hz}$ 와 16 bit였고 실효치(root mean squares)가 일정하도록 조절하 였다. 음성편집은 음성편집기(Adobe Audition 3.0; Adobe system software, San Jose, CA, USA)를 이용하여 이야기와 질문 의 간격이 1 초가 되도록 음원을 수정하였으며 각각의 이야기마 다 백색소음(white noise)을 $6 \mathrm{~dB} \mathrm{SNR}$ 을 넣었고 질문은 소음 없는 상황으로 제작하였다.

\section{연구대상}

정상청력을 가진 20 60대(평균나이 38.4세, 표준편차 14)로 구성된 총 36 명이 개발된 목록을 소음 하에서 제시했을 때 이 해 가능한가를 확인하기 위하여 참여하였다. 본 연구는 한림 국제대학원대학교 연구윤리심의위원회의 심사(\#HUGSAUD319257)를 통과한 연구이며 절차에 따라 참가자의 동의를 구한 후 실험을 진행하였다. 본 검증에 참여한 자는 앞의 1 차 검증에 참여하였던 참가자와 다르게 구성하였다. 청력측정은 $2 \times 2 \mathrm{~m}$ 규격의 소음 수준이 $30 \mathrm{dBA}$ 이하인 부스(AD229b; Interacoustics, Middelfart, Denmark) 안에서 보정을 실시한 청력검사기 (GSI 61; Grason-Stadler, Eden Prairie, MN, USA)로 실시하 였다. 참가자 모두 250 8,000 Hz에서 각각의 주파수에서 20 $\mathrm{dB}$ HL 이하의 청력이며 Korean speech audiometry-monosyllabic world level-adults(Kim et al., 2008)를 이용한 단어인 지도(WRS)는 $80 \%$ 이상이었고 이과적 병력은 없었다. 이야기 강도 수준은 피검자 각자의 쾌적레벨(most comfortable level) 에서 제시하였다.

소음 하 이야기는 소음 수준이 $50 \mathrm{dBA}$ 이하인 조용한 방에 서 음원을 재생하고 두 개의 스피커(Logitech Z623, Palo Alto,
CA, USA)로 이야기를 들려주었다. 스피커와 피검자의 거리는 약 $50 \mathrm{~cm}$ 떨어져 위치해 앉도록 하였으며 양 귀와 두 개의 스 피커와의 각도는 약 $45^{\circ}$ 를 유지하도록 하였다.

이야기를 듣고 질문에 대한 답을 하였을 때 답을 하지 못하 거나 음절단위 이상으로 오류를 보인 경우 모두 오반응으로 기 록하였다. 모든 답은 수기로 적도록 하였으며, 정반응 체크 시 발음은 같으나 종성의 자음이 다른 경우, 예를 들어 호미곶을 호미곳이라고 답한 경우는 정답으로 인정하였다.

\section{RESULTS}

총 36 명의 건청인을 대상으로 검증한 결과를 전체 정답률, 질문의 유형에 따른 차이 순으로 기술하였다.

\section{전체 정답률}

전체 정답률을 살펴보면 총 175 문항의 소음 하 이야기 중 $100 \%$ 의 정답률을 보인 소음 하 이야기는 160문항, 90 99\% 정 답률을 보인 소음 하 이야기는 10문항, 80 89\% 정답률을 보인 소음 하 이야기는 3 문항, $0 \%$ 의 정답률을 보인 소음 하 이야기 는 2 문항이었다(Table 1). 즉, 175 문항의 소음 하 이야기에 대한 전체 정답률은 $91.4 \%$ 이다.

\section{질문의 유형에 따른 정답률}

Type I의 소음 하 이야기 총 96문항 중 $100 \%$ 의 정답률을 보 인 이야기는 87 문항, $67 \%$ 의 정답률을 보인 이야기는 6 문항, $33 \%$ 의 정답률을 보인 이야기는 2문항, $0 \%$ 의 정답률을 보인 이 야기는 1문항이며, type II의 소음 하 이야기 총 79 문항 중 $100 \%$ 의 정답률을 보인 이야기는 73 문항, $67 \%$ 의 정답률을 보 인 이야기는 4 문항, $33 \%$ 의 정답률을 보인 이야기는 1 문항, $0 \%$

Table 1. Percent of correct response of story and question in noise condition

\begin{tabular}{lcccc}
\hline Percent of correction response (\%) & 100 & $90-99$ & $80-89$ & 0 \\
\hline Correct \# of items & 160 & 10 & 3 & 2 \\
Total & \multicolumn{4}{c}{175} \\
\hline
\end{tabular}

Table 2. Percent of correct response according to types of questions

\begin{tabular}{lccc}
\hline & $\begin{array}{c}\text { Percent of correct } \\
\text { response }(\%)\end{array}$ & Correct \# of items & Total \\
\hline Type I & 100 & 87 & 96 \\
& $90-99$ & 6 & \\
& $80-89$ & 2 & \\
Type II & 0 & 1 & 79 \\
& 100 & 73 & \\
& $90-99$ & 4 & \\
& $80-89$ & 1 & \\
\hline
\end{tabular}


의 정답률을 보인 이야기는 1 문항이었다(Table 2).

질문의 유형 2 가지를 나누어 검증을 해보았으나 각 질문에 대한 정답률의 차이는 크게 나타나지 않았다.

\section{DISCUSSIONS}

현대사회가 고령화 사회로 접어들면서 노인의 인구 수가 급속 히 증가하고 있고 그로 인해 난청인구도 증가하는 추세이다. 더 나은 삶의 질을 위해 보청기를 구입하는 난청인들이 늘어나고 있지만 보청기 착용과 함께 이루어져야 할 청능훈련이 국외에 비해 국내에서는 훈련 자체의 필요성에 대한 인지도가 낮을 뿐 만 아니라 여러 가지 청능훈련 도구들이 많이 부족하기 때문에 대부분의 병원이나 전문센터에서 청능훈련을 실시하지 않고 있다. 이러한 이유로 본 연구의 목적은 보청기를 착용하는 난청 인들의 의사소통 능력을 향상시킬 수 있도록 청각기술 단계 중 가장 상위 단계인 이해의 단계를 훈련할 수 있는 이야기를 이 용한 청능훈련용 도구의 개발이다. 훈련도구는 한국인에게 익 숙해야 하며, 정상청력 성인이 쉽게 이해할 수 있는 수준으로 개발하고자 하였다.

본 연구에서 수집한 최초의 200개의 이야기는 한국 성인이 친숙한 한국의 이야기를 담도록 하였다. 또한 훈련용 이야기 문 장 도구는 실제 임상에서 청능훈련 도구로 적절성 여부를 판단 하기 위하여 정상 청력을 가지고 있는 성인에게 1 차로 소음 없 이 제시하여 이해도, 난이도를 검증하였다. 그 결과, 평균 50점 이하의 점수를 받은 25 문장은 청능훈련용으로 적당하지 않다 고 판단하여 제외하였다. 2차 타당성 검증을 위하여 선정된 175 문장은 녹음과정을 거쳐 실질적으로 청능훈련 상황에서 타당 성 검증을 실시하였다. 2 차로 일상생활의 환경과 비슷하게 구 성하기 위하여 소음 하에서 재검증한 결과 대부분의 이야기에 서 $90 \%$ 이상의 정답률을 보였다. 처음 연령을 고려하여 분석하 였으나, 연령에 관계없이 모두 높은 정답률을 보여 임상에서 난 청인에게 청능훈련 도구로 적절히 사용이 가능하다고 판단하 였다.

1 차 검증과정에서 오류를 보인 문항의 이야기를 살펴보면 첫 째, 석빙고, 물두멍, 해미읍성, 복쌈, 함지박이 답안이 되는 이 야기는 일상생활에서 많이 쓰이지 않는 단어로 구성되어 있어 대답을 못하거나 자음의 오류를 보였는데, 이는 단어가 친숙하 지 않았기 때문이라고 판단하여 2차 검증 때에는 제외하였다. 둘째, 해미읍성, 복쌈, 탐라국, 호미곷, 기름틀 등의 답인 문항 은 음절을 추가하거나 탈락하게 답을 하여 $90 \%$ 미만의 정답률 을 보인 문항이었다. 이 문항들은 정상청력의 피검자들에게도 음향적으로 혼동을 가져 올 수 있어 2차 이야기 검증에서 제외 하였다.
다음으로 검증 시 질문의 유형에 따른 분석을 하였으나, 두 유형의 정답률은 거의 차이가 나지 않았다(Table 2). 가장 많은 오류를 보였던 1번 이야기와 136 번 이야기를 살펴보면 1번 이야 기의 답은 '제주'였으나 검증에 참여한 성인들은 더 익숙한 제 주도라 대답하였고 136번 이야기의 답은 '굴비'였으나 위에서 설명하였듯이 비슷한 생선 이름이 같이 제시되고 질문도 불특 정하였기 때문에 $0 \%$ 의 정답률을 보였다. 이 두 문항은 최종 청 능훈련 컨텐츠에서 제외하도록 하였다. 위와 같은 검증을 거쳐 만들어진 청능훈련용 이야기 문장들은 인간이 말소리를 이해하 기까지의 과정 즉, 탐지, 변별, 확인, 이해의 과정을 난청인들이 보청기를 착용 후 청능훈련을 통해 이 과정들을 익혀 어음이해 력을 높이고자 한다.

본 검증을 통해 청능훈련 도구 개발을 위해 $90 \%$ 미만의 정 답을 보인 총 5 문항을 제외한 170 문항의 이야기들은 건청인이 라면 누구나 이해하고 대답할 수 있다고 판단하였다. 그러나 단 답형의 답을 얻기 위해 답의 구성이 다양하지 않다는 점과 발 음이 정확한 성우가 아닌 한국어를 모국어로 사용하는 일반인 성인 여자가 녹음했다는 점에 있어서 오류가 있을 수 있다는 한계가 있다. 또한 이야기와 질문의 형식이 각각의 이야기마다 매우 비슷하여 비록 각각의 이야기가 들려주는 순서를 바꾸어 검증하였으나 많은 문항의 이야기를 듣다보면 질문의 형식을 이해하여 끝까지 듣지 않은 상태에서 답을 하는 경향을 보여 형 식을 다양하게 하여 질문을 구성할 필요성이 있다.

후속연구에서는 본 연구에서 나타난 문제점을 보완하여 좀 더 다양한 컨텐츠를 포함하고 난이도도 조절할 수 있도록 한다 면 난청인이 흥미롭게 참여할 수 있는 청능훈련 도구를 개발할 수 있을 것이라 본다. 또한 다음 연구에서는 실제적으로 난청인 이 사용하였을 때 의사소통 능력이 향상할 수 있는지에 대한 검증이 반드시 이루어져야 한다.

중심 단어 : 청능훈련·청각재활·난청인.

\section{Acknowledgments}

이 논문은 2015년 대한민국 교육부와 한국연구재단의 지원을 받 아 수행된 연구임(NRF-2015S1A5A8014708).

본 연구에 참여해 주신 난청인 분들께 감사드리며, 데이터 수집을 위하여 협조를 해 주신 오창준 원장님께 감사드립니다.

\section{REFERENCES}

Ahn, P. H. \& Lee, K. W. (2016). Development of environmental sounds for auditory training. Audiology and Speech Research, 12(2), 82-88.

ASHA. (2016). Untreated Hearing Loss in Adults-A Growing National Epidemic. Retrieved from http://www.asha.org/Aud/Articles/UntreatedHearing-Loss-in-Adults/.

Baek, S. S. \& Lee, J. H. (2016). Development of crossword puzzles for auditory training. Audiology and Speech Research, 12(2), 103-108.

Burk, M. H. \& Humes, L. E. (2008). Effects of long-term training on aided speech-recognition performance in noise in older adults. Journal of 
Speech, Language, Hearing Research, 51(3), 759-771.

Cho, Y. Y., Lee, J. H., \& Bahng, J. (2013). Case study of auditory training for an elderly hearing aid user. Audiology, 9(2), 190-194.

Chang, S. H. \& Lee, J. H. (2016). Development of auditory training tool for adults using sentences. Audiology and Speech Research, 12(2), 89-96.

Kim, J. S., Lim D., Hong, H. N., Shin, H. Y., Lee, K. D., Hong, B, N., et al. (2008). Development of Korean standard monosyllabic word lists for adults (KS-MWL-A). Audiology, 8(2), 126-140.

Korea Institute for Health and Social Affaires. (2015). The census for the disabled in Korea. Seoul: Ministry of Health and Welfare. Retrieved from http://www.index.go.kr/potal/main/EachDtlPageDetail.do?idx_ $\mathrm{cd}=2768$.

Ku, S. M., Kim, J. S., \& Lim, D. H. (2006). A summary of the census for the disabled in Korea-focusing on the hearing impaired. Audiology, 2(1), 52-57.

Kwon, Y. J. (2014). Effects of 8-week auditory training: Compressed speech and speech in noise (unpublished master's thesis). Hallym University of Graduate Studies, Seoul.

Lee, J. \& Lee, K. W. (2008). Breakthroughs in hearing aid technology and rehabilitation. Korean Journal of Audiology, 12(3), 145-151.

Lee, Y. S. (2011). Effects of training on nonsense syllable performance in noise for older hearing aid users (unpublished master's thesis). Hallym
University of Graduate Studies, Seoul.

Park, S. H., Suk, D. I., Kwon, M. J., Choi, Y. H., \& Lee, M. J. (2009). Practice in Auditory and Speech Rehabilitation. Seoul: Sigma press.

Park, Y. S. (2009). A qualitative study on the life adaptation of hard of hearing persons: focused on the participants in the self-help group of hard of hearing persons (unpublished master's thesis). Gongju University, Gongju.

Siemens. (2007). eARena ${ }^{T M}$. Retrieved from http://us.hearing.siemens.com/ pro/marrketing-support/auditory-training/.

Stacey, P. C., Raine, C. H., O’Donoghue, G. M., Tapper, L., Twomey, T., \& Summerfield, A. Q. (2010). Effectiveness of computer-based auditory training for adult users of cochlear implants. International Journal of Audiology, 49(5), 347-356.

Sweetow, R. \& Palmer, C. V. (2005). Efficacy of individual auditory training in adults: A systematic review of the evidence. Journal of the American Academy of Audiology, 16(7), 494-504.

Sweetow, R. W. \& Sabes, J. H. (2006). The need for and development of an adaptive Listening and Communication Enhancement (LACE) program. Journal of the American Academy of Audiology, 17(8), 538-558.

Yeo, S. H., Bahng, J. H., \& Lee, J. H. (2014). Efficacy of auditory training using sentences in noise for hearing aid users. Audiology, 10(1), 65-75. 


\section{APPENDIX}

\section{Examples of Type I stories}

1. 이야기: 오대산은 바위보다 흙이 많은 산으로, 다섯 봉우리마다 절이 하나씩 있습니다. 또한 오대산은 사계절 어느 때나 오를 수 있는 아름다운 산입니다.

질문: 흙이 많은 산으로 봉우리마다 절이 있는 이 산의 이름은 무엇인가요?

2. 이야기: 옛날부터 강원도에는 감자가 많이 생산되었습니다. 그래서 강원도 사람들은 감자바우라고 불러 왔습니다.

질문: 감자가 많이 생산되는 곳이어서 사람들이 감자바우라고 불렀던 이 지역의 이름은 무엇인가요?

\section{Examples of Type II stories}

1. 이야기: 부산은 항구를 개방하여 서구문화가 들어오는 항구입니다. 개항 이후 전 세계 여러 나라의 배가 부산항을 찾아와 물건 을 사고 팔았습니다.

질문: 어디에 대하여 이야기하고 있습니까?

2. 이야기: 칼국수는 집에서 쉽게 만들어 먹을 수 있는 별미입니다. 칼국수는 밀가루나 메밀가루를 반죽하여 얇게 민 다음 칼로 썰 어 끓여서 만듭니다.

질문: 어떤 음식에 관하여 이야기하고 있나요? 